\title{
Building Knowledge: The Concept of Care
}

\author{
Mary Kalfoss, Jenny Owe Cand \\ Diakonova University College, Oslo, Norway \\ Email: mary.kalfoss@diakonova.no
}

How to cite this paper: Kalfoss, M. and Cand, J.O. (2016) Building Knowledge: The Concept of Care. Open Journal of Nursing, 6, 995-1011.

http://dx.doi.org/10.4236/ojn.2016.612096

Received: November 4, 2016

Accepted: December 12, 2016

Published: December 15, 2016

Copyright $\odot 2016$ by authors and Scientific Research Publishing Inc. This work is licensed under the Creative Commons Attribution International License (CC BY 4.0).

http://creativecommons.org/licenses/by/4.0/ (c) (i) Open Access

\begin{abstract}
Aim and Objectives: The aim of this article is to explore whether the specific levels of caring described in Swanson's Middle Range Caring Theory which include characteristics of caring, people's concerns and commitments underlying caring, conditions that enhance/inhibit caring and consequences of caring and non-caring could be used in categorizing findings from two literature reviews investigating the concept of care. Background: Nursing has a long legacy as a caring/healing profession where caring is increasingly posited as one of the core concepts in modern nursing science. However, the meanings given to the concept of care remain elusive, ambiguous and unclear. Design: Two systematic literature reviews. Method: Twenty-nine articles based on strategic inclusion and exclusion criteria were synthesized. Data was retrieved from CINAHL, Medline, Embase and PsycInfo covering the period 20032016. The literature search used the key words care, concept analysis, systematic review, meta-synthesis, meta-analysis and narrative review. Results: Major themes found were related to the following characteristics of caring persons: compassionate, knowledgeable, positive and reflective. Concerns and commitments underlying caring were doing the right thing, connecting, focusing on the others' experience, acknowledging individual dignity and worth and being present. Conditions that enhanced/inhibited caring were situational constraints, personality traits, communication skills, health problems and organizational features. Consequences of caring and non-caring actions included both positive and negative emotional, spiritual, physical, and social outcomes for patients, families and nurses. Conclusion: The specific levels of caring described in Swanson's Middle Range Caring Theory are highly suitable for categorizing the findings from three literature reviews on the concept of care. Relevance to Clinical Practice: Swanson's Middle Range Caring Theory can be used to guide clinical practice and encourage an individual approach to care. It has been shown to contain clear, comprehensible language in its theoretical basis; this encourages use in clinical practice.
\end{abstract}

\section{Keywords}

Caring, Concept Analysis, Concept Development, Swanson's Middle Range

Theory of Caring, Theoretical Framework 


\section{Introduction}

Nursing has a long legacy as a caring/healing profession. Caring is increasingly posited as one of the core concepts in modern nursing science [1] [2] [3] [4] [5]. Nevertheless, it has been stated that the interest of nursing researchers in the phenomenon of caring has grown slowly over the past 10 years, and although there appears to be an increased use of the term care/caring in nursing, there has been limited interest or systematic study of the concept itself [6]. The central place of caring as the essence of nursing has also been challenged by various nursing scholars. Further, controversy exists within and outside of nursing as to the role of caring in personal and professional relationships [7]. A universal definition or conceptualization of caring does not exist, despite attempts to achieve conceptual clarity [8]. The lack of a universally accepted definition is linked to the level of maturity of a concept, with caring being described as an immature [9]. Compounding this criticism is the fact that nursing science is concerned with complex human behaviors within a continually changing trajectory of health. Consequently, concepts of interest to nursing such as caring are multifaceted, interconnected and may manifest differently at varied points along the health trajectory.

Concepts are the building blocks of theory and thus need continual exploration to clarify their meanings [10]. Huch [11] argues that concepts are not like bricks but instead are like niches and succinctly states that conceptual clarification is not possible without theoretical commitment. He argues that in the absence of theoretical commitment, concept clarification becomes an arbitrary and vacuous exercise in semantics. Therefore, theoretical commitment to concept development should be of upmost importance and nurses should continually strive to verify existing theoretical structures, also in existing nursing theories [12].

Swanson's theory of caring is considered a middle range theory. Middle range theories are more concrete and narrower than grand theories, being composed of a limited number of concepts and positions described relatively concretely on a specific level. When a middle range descriptive theory describes a phenomenon, it describes the commonalities found in observations of individuals, groups, situations and events and categorizes the commonalities into mutually exclusive, overlapping, hierarchical or sequential dimensions. Swanson's Middle Range Caring Theory was developed over a series of clinical research studies in women's health [13]. She also conducted an extensive meta-analysis of 130 studies of caring which led her to conclude that knowledge about caring could be categorized into five levels of caring [13]. Consequently, her theory provided both a conceptual framework and empirical support for the generalizability of the theory beyond clinical contexts from which it was generated. The five levels described by Swanson are as follows: Level 1portrays characteristics of persons with the capacity for caring with a focus on how the caring person has traits which are both inherent and influenced by the environment. Level 2 describes concerns and commitments which focus on the beliefs or values that under pin caring actions. Level 3 includes conditions and circumstances that enhance or inhibit caring which are related to the patient, nurse, or organization. Level 4 is described as concrete caring actions, be- 
haviors and therapeutic interventions. This level is not included in this paper due to the vast amount of data and will be published separately. Lastly, Level 5 focuses on the positive and negative consequences of caring which may consist of both intentional and unintentional outcomes for the provider and/ or recipient [13]. Notably, in Swanson's earlier work, she discussed how these five caring levels are interconnected and states “... caring begins with a fundamental belief in persons and their capacity to make it through events and transitions and face a future with meaning" [14]. She regarded maintaining belief in the person as the basis of nursing care. She also described how the five levels overlap each other, and indicated that their relationship to each other may also be hierarchical [14]. However, others have found that the caring levels occur simultaneously [15].

\section{Aims and Method}

The aim of this article is to explore whether specific levels of caring in Swanson's Middle Range Caring Theory could be used in categorizing findings from the literature reviews here, study will be made of characteristics of caring persons, concerns and commitments underlying caring, conditions that enhance/inhibit caring and consequences of caring and non-caring.

\subsection{Design}

The study was carried out using a systematic literature review based on concept analysis, meta-analysis or narrative review.

\subsection{Data Collection}

A systematic literature review was made in the CINAHL, Medline, Embase, PsycInfo databases covering the period January 2003-December 2013, updated from January 2014 to May 2015. Key words included care AND concept analysis AND limitations which included timeline, review OR systematic review OR meta-synthesis OR meta-analysis OR narrative review. The first search resulted in 414 citations. The title and abstract of these citations were reviewed independently by the authors. During this process, 291 citations were excluded due to the titles were not relevant, in duplicate form, and/or not written in English. The 123 citations found relevant were retrieved for further evaluation. The titles and/or abstracts of these citations were again reviewed independently based upon the following inclusion criteria; the word care/caring was present in the title or the abstract, written in English and the paper provided a concept analysis, a systematic review, a meta-analysis or meta-synthesis. Duplicate citations were again excluded. The search resulted in 35 articles which were fully retrieved. After detailed reading, a further six articles were deleted as they did not discuss care or caring per se, did not apply an explicit method of concept analysis or the findings did not reflect the perspectives of staff, care recipients, or family members. Upon the second reading of the remaining 29 articles, a further four were excluded because they did not discuss care or caring per se or describe their literature review methodology. In the 
second search from 2014-2016, based upon the same inclusion criteria, an additional four articles were found. All decisions to exclude articles were made by consensus between the two authors. The final sample included 29 articles. During both reviews, the authors attempted to follow the "Preferred Reporting Items or Systematic Reviews and Meta-Analysis Statement (PRISMA) statement. No attempt was made to locate further references by manual searching due to limited time and resources. Although manual searching is often recommended, it also carries with it the possibility of introducing human error and retrieval bias. Refer to Figure 1 which plots the data extraction process.

\subsection{Data Analysis}

Data analysis consisted of reading each article attentively to allow immersion in the data and comprehend meanings given to the concept of caring.The analysis was carried out according to the thematic analysis procedure described by Miles and Huberman [16]. Thus, all categories of data were evaluated in order to identify the emerging topics in the listed articles. Categorization at broad, topical levels occurred first. Then clusters of phenomena were devised using a constant comparative method. Data were read

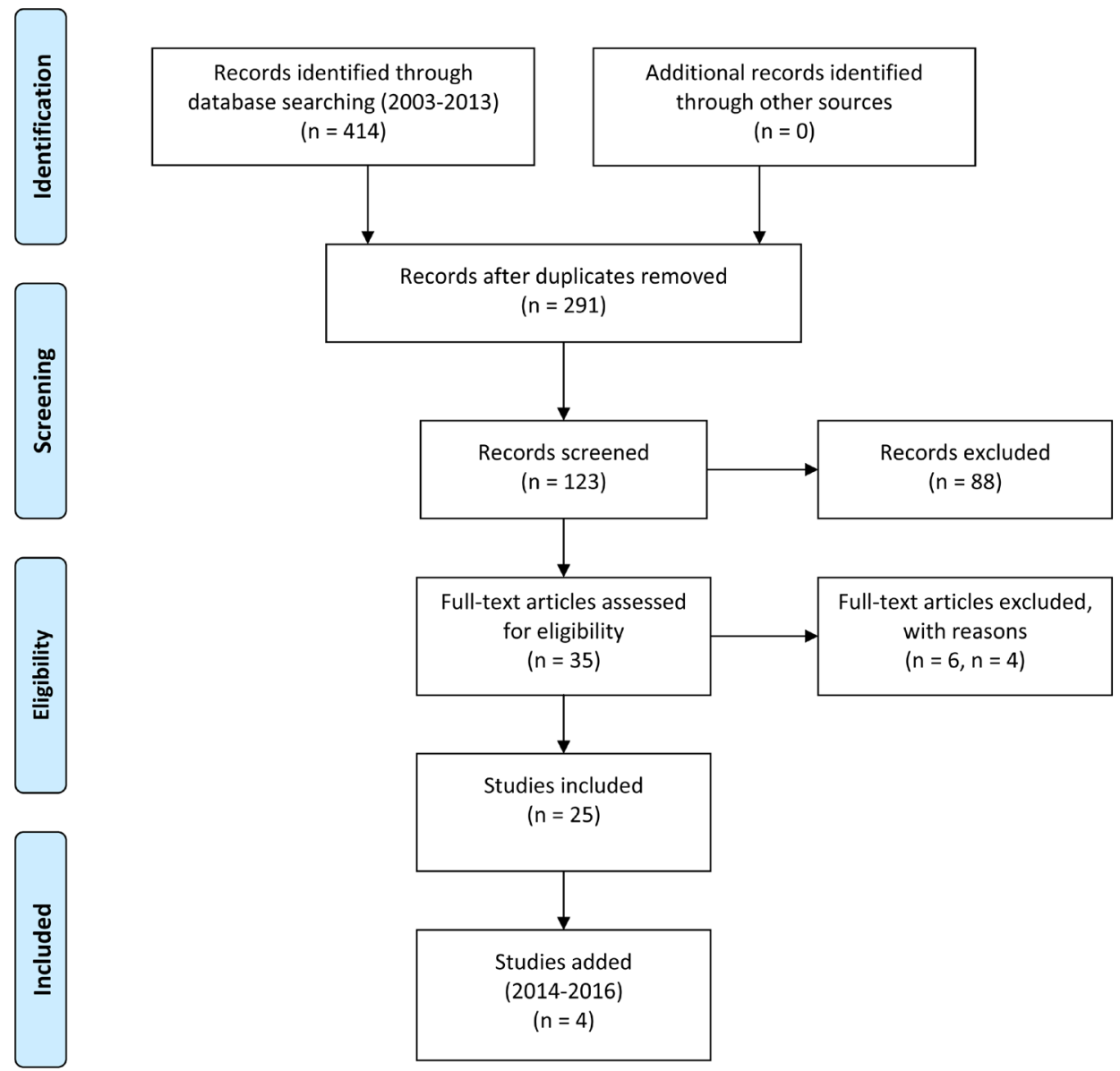

Figure 1. Literature identification process. 
thoroughly and assigned descriptive words and phrases. An attempt was made to preserve the rich details of the findings as descriptions at the cluster levels. Further classification of data under these categories was then recoded in accordance with Swanson's caring levels described as characteristics of caring persons, concerns and commitments underlying caring, conditions that enhance/inhibit caring, and consequences of caring and non-caring. The second author (JO) read through the classification schemes, raised questions and suggested alterations. Both authors discussed the classification of findings until agreement was reached. A log book was used to write down reflections supporting the reliability of the study.

\section{Results}

\section{Characteristics of caring persons (Level 1)}

Characteristics of caring persons include being compassionate, which embodies being friendly, courteous, interested, concerned, nurturing, ministering, diplomatic, authentic, cherishing, sensitive and loving [17]-[24]. A further characteristic is being knowledgeable, which consists of being engaged, competent, confident and respectful [17] [19] [24] [25]. Being empathetic is another characteristic, which embodies listening, showing concern for patients' privacy, responding promptly, provision and/or management of pain relief, giving time to speak, showing sympathetic presence and being cautious in avoiding harm [17] [18] [19] [20] [23] [24] [25] [26]. Another characteristic is being positive which includes having a positive outlook, having positive personal qualities and feeling and exhibiting concern for others [18] [19] [23] [25]. Lastly, the characteristic of being reflective embodies being conscientious, protective, diligent, attentive and committed with an attitude of warmth, openness and willingness to share responsibility [20] [27].

\section{Concerns and commitments underlying caring (Level 2)}

The concerns and commitments underlying caring include a commitment to doing the right thing which is grounded in moral and ethical obligations, standards and policies for practice and values and social norms. This rests on ethical principles of nonmalevolence and beneficence, and ethical ways of knowing what is nonjudgmental [19] [22] [23] [24] [26] [27] [28] [29] [30].

Other concerns and commitments include connecting with the other, which is characterized by a contextually negotiated reciprocity. It is compassionate, caring, honest, sincere, confident, and is based on a mutual commitment of health professional and family members to engage in a healing process. It also reflects a partnership that shares common goals and is committed to a way of being [18] [24] [25] [26] [27] [28] [31]. Focusing on the other's experience relates to having a humanistic view of the patient, understanding the patients' lived experience and recognizing the patient as a spiritual being. The patient may believe in God, a supernatural being, a life force, or a spiritual force with a dynamic quest for a transcendent relationship [23] [26].

Concerns and commitments also embody acknowledging the dignity and worth of each person. This is a holistic quality, emphasizing respect for individual and cultural 
differences and accepting variability [18] [21]-[28] [32]. Being present to the self is another concern. This involves the nurse's internal perceptions, values and decisional processes, attitudes and positioning within relationships and an understanding of patients' capabilities: these include individual identities, needs, and self-evaluations [26] [33]. Being present also means being competent: here, work style and motivation are important. Also involved are the professional's personal sense of commitment, responsibility, consideration, sympathy, giving of self and is ability to discern the other's growth potential [18] [19] [34].

\section{Nurse-patient and organizational conditions affecting caring (Level 3)}

Nurse-related factors affecting the relationship with the patient include conditional constraints which are related to emotional demands, power imbalances, frequency and intensity of care, work complexity and social norms [20] [35]. Other constraints are lack of clear definitions of patient-centered care, inadequate education, lack of collaboration, coordination and continuity of care, staff shortage, lack of good teaching models and curriculum on patient centered care, dominance of biomedical model perceptions, economic constraints and patient complexity [22] [35] [36]. Personality characteristics will also affect emotional adaptability, and be dependent on the nurse's societal culture and ethical and religious beliefs [19] [20] [35].

Patient-related conditions which affect the relationship and communication are the patient's openness to nursing and the patient's attitude and behavior. The patient may be angry, aggressive, overly demanding, not consciously aware, or fearful and anxious. Communication is also influenced by the varied emotional responses found in women and men [17] [27] [35] [37]. Caring is also affected by patient characteristics such as age, ethnicity, education, personal abilities, lifestyle, prior abuse and self-rated health [37] [38]. Other patient-related factors are the patient's health problems such as diagnostic/therapeutic/care uncertainty, chronic status, physical function/disability, illness and symptom severity, instability, complications, comorbidities, emergency hospitalization and criticality [38]. Other health problems include pain which is not assessed and treated, cognitive impairment, complex, unpredictable trajectories and geriatric syndromes, frailty and insurance limitations. Nurses may have to resuscitate patients with a persistent vegetative state or give mechanical ventilation support to patients with only a few days to live [29] [35].

Organizational conditions which affect caring include administrative support which is professionally centered on medical and patient models of care, emphasizing care and regard nurses as experts [26] [27]. Other organizational factors are organizational rules, organizational teamwork, and number and type of nurses/assistive caregivers including their competency level, education, and past experience [19] [39]. Administrative support also consists of available and adequate resource allocation such as number of beds, medications and supplies, and functioning equipment [19] [22] [27] [35] [36] [39]. Administrative support also consists of organizational environments which actively promote emotional support exchanges, lead in developing and adapting innovative patient centered care models, identify needs for support in self-awareness and review 
staffing/education policies in regard to suboptimal care [19] [21] [26] [35].

Other organizational conditions influencing caring include personnel-or role-related factors. These may involve nurses consciously or unconsciously regulating patient's possibilities for participation or refraining from communicating in order to avoid conflict. A further factor is physicians who are inadequately trained in self-management, nurses who experience caring themselves and have team support and reasonable work expectations [25] [27] [31]. Other factors are effective staff relationships with regularly scheduled meetings, interdisciplinary team actions, the planning of care and pain management and continued education, mentoring and support for nurses [32]. Work or practice condition is another organizational factor, these may involve patient care demands, time allotment, and a working environment that contributes to a caring health care system [26] [27] [32] [39]. Other work conditions consist of fragmented, uncoordinated care, power dominance, nurses having to perform non-professional duties, patients receiving potentially conflicting self-management regimes and communication problems in multiple settings [26] [27] [29] [35] [38]. Other factors are supportive environments conducive to reflection, understanding and discussing emotional labor in caring for difficult patients, and interdisciplinary support to identify compassion fatigue and stressors which contribute to negative behaviors [19] [21]. Lastly, technol$o g y$ is another organizational condition; here the level of technology and availability of equipment are important [26] [31] [36] [38].

Consequences of caring and non-caring for patients, families and nurses (Level 5)

\section{Positive consequences for patients}

Notably, sixteen papers described positive consequences of caring for patients as including emotional-spiritual outcomes such as improved quality of life, general wellbeing, satisfaction with care, and healing relationships with self, others and religious icons [18] [22] [23] [24] [26] [27] [29]-[34] [40] [41]. Emotional-spiritual outcomes also include personal growth and self-actualization, reduced mortality, increased autonomy and inner control, feeling valued and respected, and the preservation of valued capabilities [26] [27] [33] [42]. Other consequences include self-respect and self-esteem, improved meaning, increased problem solving, relief from suffering, improved pain control, discovery of new possibilities, and help to face an optimal and peaceful death [18] [21] [25] [26] [28] [31] [38] [40] [41] [42]. Further outcomes are a sense of freedom and responsibility, enhancing a positive mental attitude, happiness, and reduction of stress, fear and anxiety [27] [33] [42]. Enhanced human dignity (finding a sense of worth and reason to live), finding meaning in life in regard to issues of suffering, providing future hope, and enabling the discovery of new potentials are other positive outcomes [17] [23] [34] [40]. Physical aspects represent another positive outcome and consist of improved health, improved healing and a sense of security and safety which enhances functioning and independence [17] [18] [22] [24] [27] [30] [31] [34] [41]. Similarly, maintaining patient autonomy, sense of control, self-efficacy, competence, self-confidence, empowerment, opportunities for decision making, increased patient 
adherence, increased reality orientation, positive behavior changes, successful coping and increased strength to deal with illness are other physical outcomes [17] [18] [22] [24] [27] [31] [40] [41] [42].

Positive consequences for patients also embrace social aspects such as increased use of health care services, increased health promotion, improved health care utilization, improved relationships with others, and increased sense of solidarity [17] [18] [34] [41].

Negative consequences for patients

Negative outcomes for patients include emotional-spiritual consequences such as negative input on quality of life [35] [38] [43]. They also include physical consequences such as death, resuscitating patients to a life attached to equipment, harming patients, anxiety, post-traumatic stress symptoms, increased cardiac arrests, increased severity of health care problems, increased hospital stays, spiritual distress, multidimensional vulnerability, behavioral problems and avoidance of health care systems [22] [24] [35] [37] [38] [43].

\section{Positive outcomes for families}

Positive outcomes for the family include emotional-spiritual outcomes such as strengthened coping abilities and sense of control, decreased psychological distress, reduced guilt, improved bereavement outcomes, empowered individual resources, reduced powerlessness, strengthened family health functioning and integrity, and the preservation of dignity [25] [27] [32] [44]. Social consequences include improved bonding between parents and their family, extended relationships with other families, more open and honest relationships with decreased conflict and anger, mutually satisfactory collaboration, and enhanced communication between patients, families and staff [16] [22] [30].

\section{Negative outcomes for families}

Negative emotional-spiritual outcomes for the family are futile care, burdened sense of responsibility, vigilant behavior and financial strain [25] [35]. Professional consequences in family-centered care may involve a blurring of roles and professional identity, which result in nursing actions focused on their unconscious need for control. A further factor is disagreement between families, nurses, leading to moral dilemmas for nurses [25].

\section{Positive outcomes for nurses}

Positive emotional-spiritual outcomes for nurses include emotional-spiritual consequences which include improved quality of life, increased mental well-being, renewed energy and passion, increased empathy and sensitivity, management of negative feelings, reduced stress, enhanced ability to face denial of death in patients and increased personal growth and self-actualization [17] [20] [21] [27] [34] [41].

Other positive outcomes include professional consequences such as increased expertise and understanding of the patient's situation, self-confidence, job satisfaction, professional pride, increased holistic and safe care, and improved empathy [17] [18] [20] [22] [24] [25] [27] [30] [31] [32] [34] [39] [40]. Similarly, individual care involving improved communication, conflict reduction and growth development in both nurse and 
patient will promote nurse empowerment, self-esteem, self-management, and result in enhanced service performance with emotional engagement and a sense of professional and personal accomplishment [19] [25] [27] [31] [40] [41].

Positive social consequences for nurses include the development of relational and other skills and improved problem solving, decision making and goal attainment. Nurses may gain greater role clarity, improve and enhance reflection, learning and sharing of skills, facilitates team approach, and enhances consistency of information [22] [30] [34] [40] [41] [45].

\section{Negative consequences for nurses}

Negative emotional-spiritual outcomes for nurses include loss of empathy, accident proneness, emotional breakdown and burnout, negative emotional distortions, emotional stress, emotional exhaustion, depersonalization, increased guilt and shame, weight loss, and sympathetic over-awareness arising from over-identification and overinvolvement [19] [20] [37] [38] [43]. Other negative professional are sickness absences, inaccurate perception of patient experiences leading to suboptimal care, conflict within the medical teams and with patients and communication problems [38] [43]. Nurses can also have egoistic motivation to alleviate their own distress by overly helping patients. They may not understand the patient's frame of reference or impose their interpretations of the patient's situation. This may result in decreased empathy and emotional bonding in the relationship with the patient [20].

Positive and negative consequences for the health care system

Positive consequences for the health care system include the creation of a therapeutic culture, which includes improved quality of care, increased preventative services, a cheerful environment and greater continuity of care. It also involves decreased movement of patients during hospitalization, increased productivity, and enhanced public and patient confidence with fewer patient complaints [19] [22] [26] [37] (see Figure 2).

\section{Discussion}

Applying Swanson's levels of caring as a conceptual framework, the results of Level 1, which describes caring traits composed of both inherent and environmental-related qualities, showed that the major characteristics of caring persons included being compassionate, knowledgeable, empathetic, positive and reflective. Level 2 which focuses on beliefs and values that underpin caring actions showed that major concerns and commitments underlying caring were doing the right thing, connecting with the other, focusing on the other's experience, acknowledging individual dignity and worth, and being present to self. Level 3 which concerns factors which enhance or inhibit caring for the nurse, were conditional constraints, personality characteristics and communication. Patient-related conditions affecting caring were patient's health problems, degree of administrative support, and technological aspects. Level 5 which focuses on the positive and negative consequences of caring concerning patient's included emotional-spiritual, physical and social consequences, for the patient, emotional-spiritual, physical and social outcomes for nurses and the emotional-spiritual, social and professional conse- 


\section{Characteristics of Caring Persons}

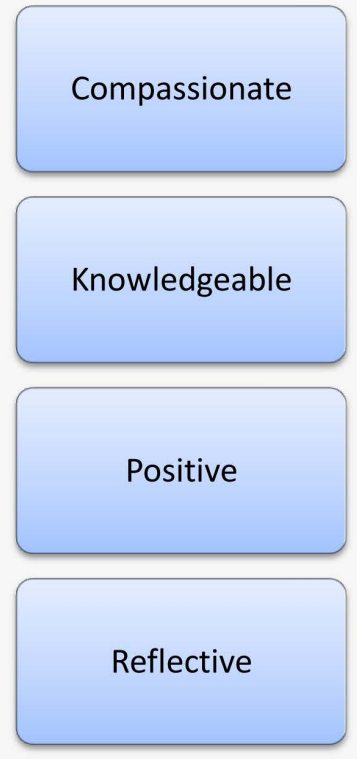

Concerns and Commitments Underlying Caring

Doing the right thing

Connecting with other

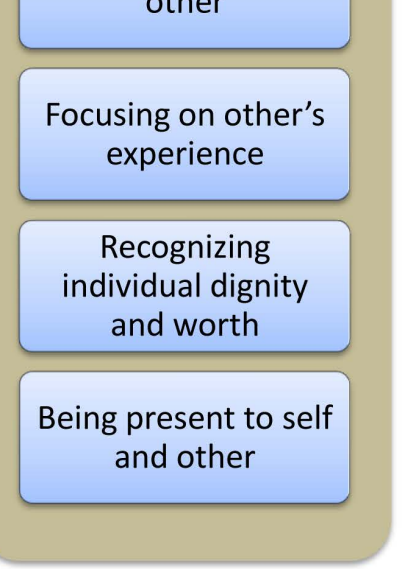

Conditions that Enhance/ Inhibit Caring

Nurse

- Conditional constraints - Personality characteristics

Patient

- Communication

- Health problems

Organizational

-Administrative

- Personnel or role related

conditions

-Work or practice related

conditions

-Technological aspects
Consequences of Caring and Non-

Caring

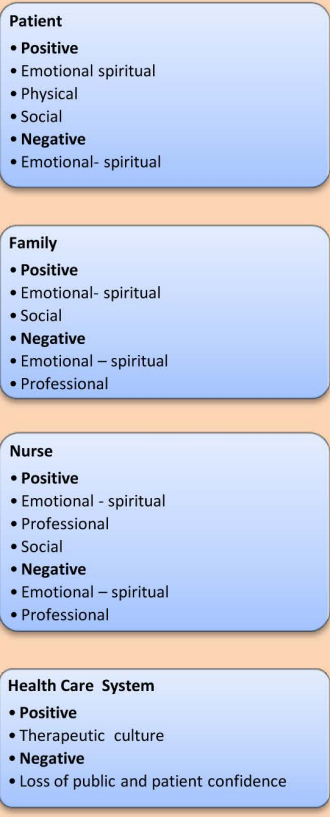

Figure 2. Characteristics of Swanson's caring levels.

quences for the family. Consequences while negative/consequences included emotionalspiritual and social outcomes. Both positive and negative caring consequences for nurses included emotional-spiritual, professional and social outcomes. For family, positive and negative outcomes included emotional-spiritual, social consequences and professional consequences. Positive and negative consequences for the health care system which affected caring included impacts on the therapeutic culture. Notably, the definitions of Swanson's levels of caring in her theory of caring were found to be semantically clear and provided a useful conceptual framework for classifying results from a systematic literature review. This semantic clarity of Swanson's concepts has been supported by others [42].

One of the most outspoken critics of the use of the concept of care in nursing [45], proposed that nursing theory in the ethics of care be postponed indefinitely because it is incapable of doing the work that nurses need to do. We disagree with this contention.

Swanson's Middle Range Theory of Caring has received considerable attention around the world with its usefulness being demonstrated in research, education and clinical practice [42] [46]. The results of this study also support the applicability of the theoretical constructs in categorizing findings from literature reviews.

Many decades ago, Glaser \& Strauss [47] stated that theories should be able to ad- 
vance theory development, guide practice, offer perspectives on behavior, serve a means of interpreting data and provide an approach style for research in specific areas of human behavior. Further and more recently, Watson [48] underlined that the next generation of theory, research, methods and measurements requires conceptual and operational space to develop and validate new grand theories, mini-theories, middle-range theories and situation-specific theories. This can be achieved through the exploration and uncovering of old and new relationships and new understandings about the phenomenon of caring. She contends that the demand for theory-guided, theory-based and theory-located contexts for evidence is becoming greater due to current and cultural demands for evidence and outcomes ([48], p. 271). The findings of this study support the applicability of Swanson's caring levels as an analytic tool and hopefully demonstrate linkages between theoretical constructs and evidence-based indicators.

The results also seemingly support the multidimensionality of care/caring as a complex, subjective, intersubjective, relational, personal and professional human phenomenon. Given the complexity of caring as a concept, conceptual differences regarding caring are inevitable [49]. These differences can enrich, although at the same time hinder, communication regarding our understandings about caring. Some dialectic debates regarding caring have also centered on the tautological nature of care, with criticism focusing on the needless repetition of the same sense of meaning of caring, or idea of caring, being said with different words [50]. Conversely, Sargent [51] contends that caring should be reframed as discursive practice that is fluid and contingent rather than a fixed conceptual entity. On the other hand, Paley [29] claims that nurses do not discriminate between perceptions of caring, the concept of caring, the experience of caring and caring itself. However, much of Paley's criticism focuses on what he describes as the inability to separate the dual components of nursing-attitudes/values and activities ([52], p. 188). The rich diversity of our findings under the various levels offers support for Swanson's suggestion that professional discussion on the concept of caring in nursing might best be characterized as having different levels of discussion. When referring to the concept caring, she states, "there is a need to be clear about whether the discourse is about the capacity for caring, the concerns and commitments that underline caring, conditions that inhibit or enhance caring, caring actions, or the consequences of caring" ([13], p. 63).

Watson [5] has previously given credit to the theoretical and empirical work of Swanson. Our findings also demonstrate congruence with the 10 carative factors found in Watson's Theory of Caring. These carative factors include: the formation of a humanistic altruistic system of values, the instillation of faith-hope, the cultivation of sensitivity to one's self and to others, the development of a helping-trusting relationship, expressing positive and negative feelings, the systematic and creative use of scientific problems-solving method for decision making, the promotion of interpersonal teaching-learning, the provision for a supportive, protective, and/or corrective mental, physical, sociocultural, and spiritual environment, assistance with the gratification of human needs, and the allowance for existential-phenomenological spiritual forces. For example, the formation of a humanistic-altruistic system of values and being authenti- 
cally present and opening up to others can be seen in our results as characteristic in Level 1 and 2 in Swanson's Caring Theory. The instillation of faith-hope can be seen as an outcome in Level 5, while the cultivation of sensitivity to one's self and to others can be seen in Level 2, developing a helping-trusting relationship and being authentic are characteristics of Levels 1, 2, 3 and 5, also together with characteristics of non-caring. The expression of positive and negative feelings and provision of a supportive, protective mental, physical, sociocultural, and spiritual environment and assistance with human needs can be seen in Levels 2, 3 and 5. The systematic and creative use or non-use of scientific problems-solving method for decision making can be observed in Levels 3 and 5. Further, the promotion of interpersonal teaching-learning is found in Levels 3 and 5, and the allowance for existential-phenomenological spiritual forces can be seen in Levels 2 and 5. Consequently, the findings of this study lend validation to both caring theories.

\section{Limitations to the Study}

Regarding the limitations of this study, the notable variation in findings may be due to bias in the selection of relevant literature upon which the different forms of concept analyses were based. Most articles were written by nurses which represents a specific disciplinary status. Very few articles were found based on the patient's perceptive. Further, no manual searching was undertaken as stated earlier due to limited time. As the purpose of the paper was to produce a sample of the application of the concept, in medicine, psychology and nursing research, limiters were set to reflect a rather narrow definition of the scientific literature. Only studies that were considered a form of concept analyses, systematic review, a meta-analysis or meta-synthesis or meta analysis were included as the authors meant these studies represented high quality evidence. Further, only studies which had the term care or caring in their title and/or abstract were found applicable. This was done to ensure a high degree of subject specificity. The desire for subject specificity could have been too restrictive and sacrificed the theoretical richness of the nature of the concept. Names given to the major themes and sub-themes were discussed by two independent researchers to enhance validity; however, the selected terminology used in classifying themes and sub-themes in this study is biased toward specific nursing knowledge. Interpretations of the data may have been enhanced by inviting people with different expertise to discuss the interpretation of the findings. We also confined our search to the past 13 years, which provide little historical perspective on the nature of the concept. Although this is a contemporary view of the concept of caring, we believe that concepts are dynamic, impacted by changing sociocultural influences and represent a probable truth at a certain point in time. Consequently, we do not regard a concept analysis as a static product ([10], p. 404).

\section{Conclusion}

Middle range nursing theories, like Swanson's theory, can help nurses to conduct sound nursing research ([53], p. 39). Notably, three decades ago Meleis [12] argued that since 
nursing has developed many competing and complementary theories, the debate on the validity of these theories should contribute to the scholarly development of nursing as a discipline over time. Consequently, an important process in the development of nursing knowledge is the continued analysis, evaluation and synthesis of existing nursing theories. The findings of this study support the validity and applicability of Swanson's caring levels described in her Caring Theory as an analytic tool in classifying results from literature reviews.

\section{Relevance to Clinical Practice}

Swanson's Middle Range Caring Theory can be used to guide clinical practice and encourage an individual approach to care. It has been shown to contain clear, comprehensible language in its description of theoretical levels, which has encouraged its use in practice.

Caring theories need to be expanded and translated into useful practice models and into measures and testable protocols that are employed in replicable research designs. Importantly, praxis should be informed practice-empirically validated and informed not only by one's philosophical/ethical/theoretical orientation, but grounded in concrete actions and behaviors that can be empirically assessed and measured. The difficult task for clinicians is to find a way to demonstrate how caring practices and professional models of care grounded in theoretical caring processes, such as Swanson's theory, make a difference in nursing, patient, or organizational outcomes [3] [45]. For example, the Carolina Care Model (University of South Carolina) has operationalized Swanson's Caring Theory and change clinical practice to ensure consistently high standards of practice. This model is one approach to actualizing caring theory across health care organizations by systematically incorporating interventions that link nursing actions, caring processes and expectations [51]. Numerous hospitals and health care facilities have since adopted the theory as a guide to their own nursing services, in e.g. in the US, Canada and Sweden [54]. Although her theory was originally conceived within a perinatal concept, it has been successfully applied across a wide spectrum of nursing care, demonstrating an easily understood and readily applicable theory in the context of nursing practice. Swanson's theory of caring has also been the theoretical foundation for numerous research studies. Consequently, it is a relevant theory for modern nursing research. Regarding the future implications of our results, we support Swanson's contention that nurses' professional challenges include the production/evaluation of clinical practice models and psychometrically sound measures for examining each level of caring, careful examination of associations within and among the caring levels and a commitment to framing nursing intervention studies in the language of caring. This will provide a measurable and conceptually congruent framework for a sound theoretical basis for effective clinical practice [13].

\section{Acknowledgements}

The authors are grateful to Diakonova College in Oslo for financial support of this 
study. Special appreciation is given to Vidar Bruntl and Steder for his help in creating the figure of the results. The authors are also appreciative of the work of their anonymous reviewers.

\section{Contributions}

MK was responsible for the study conception and design. JO was responsible for acquisition of data. MK and JO analyzed the data. MK drafted the manuscript. MK and JO made critical revisions to the paper regarding important intellectual content.

\section{References}

[1] Baughan, J. and Smith, A. (2008) Caring in Nursing Practice. Pearson Education Limited, Essex, UK.

[2] Benner, P.E. (1994) Interpretive Phenomenology: Embodiment, Caring, and Ethics in Health and Illness. Thousand Oaks, SAGE Publications, California.

[3] DiNapoli, P.P., Nelson, J., Turkel, M. and Watson, J. (2010) Measuring the Caritas Processes: Caring Factor Survey. International Journal for Human Caring, 14, 16-21.

[4] Swanson, K.M. (1999) What Is Known about Caring in Nursing Science: A Literay MetaAnalysis. In: Hinshaw, A.S., Feetham, S. and Shaver, J., Eds., Handbook of Clinical Nursing Research, Sage Publications, Thousand Oaks, Calif, 31-60. https://doi.org/10.4135/9781412991452.n3

[5] Watson, J. (2005) Caring Science as Sacred Science. F. A. Davis, Philadelphia.

[6] Gaut, D.A. (2013) Development of a Theoretically Adequate Description of Caring. In: Smith, M.C., Turkel, M.C. and Wolf, Z.R., Eds., Caring in Nursing Classics: An Essential Resource, Springer, New York, 271-281.

[7] Smith, M.C. (1999) Caring and the Science of Unitary Human Beings. Advances in Nursing Science, 21, 14-28. https://doi.org/10.1097/00012272-199906000-00006

[8] Sumner, J. (2006) Concept Analysis: The Moral Construct of Caring in Nursing as Communicative Action. International Journal for Human Caring, 10, 8-16.

[9] Morse, J.M. (2000) Exploring Pragmatic Utility: Concept Analysis by Critically Appraising the Literature. In: Rodgers, B.L. and Knafl, K.A., Eds., Concept Development in Nursing. Foundations, Techniques, and Applications, Saunders, Philadelphia, 333-352.

[10] Penrod, J. and Hupcey, J.E. (2005) Enhancing Methodological Clarity: Principle-Based Concept Analysis. Journal of Advanced Nursing, 50, 403-409. https://doi.org/10.1111/j.1365-2648.2005.03405.x

[11] Huch, M.H. (1995) Nursing and the Next Millennium. Nursing Science Quarterly, 8, 38-44. https://doi.org/10.1177/089431849500800108

[12] Meleis, A.I. (1997) Theoretical Nursing: Development and Progress. 3rd Edition, Lippincott, Philadelphia.

[13] Swanson, K.M. (2013) Empirical Development of a Middle Range Theory of Nursing. In: Smith, M.C., Turkel, M.C. and Wolf, Z.R., Eds., Caring in Nursing Classics. An Essential Resource, Springer, New York, 211-221.

[14] Swanson, K.M. (1991) Empirical Development of A Middle Range Theory of Caring. Nursing Research, 40, 161-166. https://doi.org/10.1097/00006199-199105000-00008

[15] Andershed, B. and Olsson, K. (2009) Review of Research Related to Kristen Swanson's Middle-Range Theory of Caring. Scandinavian Journal of Caring Sciences, 23, 598-610. 
https://doi.org/10.1111/j.1471-6712.2008.00647.x

[16] Miles, M.B. and Huberman, A.M. (2002) The Qualitative Researcher's Companion. Sage, Thousand Oaks.

[17] Brilowski, G.A. and Wendler, M.C. (2005) An Evolutionary Concept Analysis of Caring. Journal of Advanced Nursing, 50, 641-650. https://doi.org/10.1111/j.1365-2648.2005.03449.x

[18] Dalpezzo, N.K. (2009) Nursing Care: A Concept Analysis. Nursing Forum, 44, 256-264. https://doi.org/10.1111/j.1744-6198.2009.00151.x

[19] Huynh, T., Alderson, M. and Thompson, M. (2008) Emotional Labour Underlying Caring: An Evolutionary Concept Analysis. Journal of Advanced Nursing, 64, 195-208. https://doi.org/10.1111/j.1365-2648.2008.04780.x

[20] Lobchuk, M.M. (2006) Concept Analysis of Perspective-Taking: Meeting Informal Caregiver Needs for Communication Competence and Accurate Perception. Journal of Advanced Nursing, 54, 330-341. https://doi.org/10.1111/j.1365-2648.2006.03815.x

[21] Noble, H., Kelly, D., Rawlings-Anderson, K. and Meyer, J. (2007) A Concept Analysis of Renal Supportive Care: The Changing World of Nephrology. Journal of Advanced Nursing, 59, 644-653. https://doi.org/10.1111/j.1365-2648.2007.04383.x

[22] Pelzang, R. (2010) Time to Learn: Understanding Patient-Centred Care. British Journal of Nursing, 19, 912-917. https://doi.org/10.12968/bjon.2010.19.14.49050

[23] Tjale, A.A. and Bruce, J. (2007) A Concept Analysis of Holistic Nursing Care in Paediatric Nursing. Curationis, 30, 45-52. https://doi.org/10.4102/curationis.v30i4.1116

[24] Wagner, D. and Bear, M. (2009) Patient Satisfaction with Nursing Care: A Concept Analysis within a Nursing Framework. Journal of Advanced Nursing, 65, 692-701. https://doi.org/10.1111/j.1365-2648.2008.04866.x

[25] Mikkelsen, G. and Frederiksen, K. (2011) Family-Centered Care of Children in Hospital-A Concept Analysis. Journal of Advanced Nursing, 67, 1152-1162. https://doi.org/10.1111/j.1365-2648.2010.05574.x

[26] Lusk, J.M. and Fater, K. (2013) A Concept Analysis of Patient-Centered Care. Nursing Forum, 48, 89-98. https://doi.org/10.1111/nuf.12019

[27] Finfgeld-Connett, D. (2008) Meta-Synthesis of Caring in Nursing. Journal of Clinical Nursing, 17, 196-204.

[28] Hemati, Z., Ashouri, E., AllahBakhshian, M., Pourfarzad, Z., Shirani, F., Safazadeh, S., Ziyaei, M., Varzeshnejad, M., Hashemi, M. and Taleghani, F. (2016) Dying with Dignity: A Concept Analysis. Journal of Clinical Nursing, 25, 1218-1228. https://doi.org/10.1111/jocn.13143

[29] Lee, S.M. and Coakley, E.E. (2011) Geropalliative Care: A Concept Analysis. Journal of Hospice \& Palliative Nursing, 13, 242-248. https://doi.org/10.1097/NJH.0b013e318214b6cc

[30] Malusky, S.K. (2005) A Concept Analysis of Family-Centered Care in the NICU. Neonatal Network, 24, 25-32. https://doi.org/10.1891/0730-0832.24.6.25

[31] Kawi, J. (2012) Self-Management Support in Chronic Illness Care: A Concept Analysis. Research and Theory for Nursing Practice, 26, 108-125.

https://doi.org/10.1891/1541-6577.26.2.108

[32] Stayer, D. (2012) Pediatric Palliative Care: A Conceptual Analysis for Pediatric Nursing Practice. Journal of Pediatric Nursing, 27, 350-356. https://doi.org/10.1016/j.pedn.2011.04.031

[33] Entwistle, V., Firnigl, D., Ryan, M., Francis, J. and Kinghorn, P. (2012) Which Experiences 
of Health Care Delivery Matter to Service Users and Why? A Critical Interpretive Synthesis and Conceptual Map. Journal Health Service Research Policy, 17, 70-78.

https://doi.org/10.1258/jhsrp.2011.011029

[34] Hudon, C., St-Cyr Tribble, D., Bravo, G. and Poitras, M.E. (2011) Enablement in Health Care Context: A Concept Analysis. Journal of Evaluation in Clinical Practice, 17, 143-149. https://doi.org/10.1111/j.1365-2753.2010.01413.x

[35] Bahramnezhad, F., Cheraghi, M.A., Salsali, M., Asgari, P., Khoshnava Fomani, F., Sanjari, M. and Farokhnezhad Afshar, P. (2014) Futile Care. Concept Analysis Based on a Hybrid Model. Global Journal of Health, 6, 301-307. https://doi.org/10.5539/gjhs.v6n5p301

[36] Quirke, S., Coombs, M. and McEldowney, R. (2011) Suboptimal Care of the Acutely Unwell Ward Patient: A Concept Analysis. Journal of Advanced Nursing, 67, 1834-1845. https://doi.org/10.1111/j.1365-2648.2011.05664.X

[37] Bruggemann, A.J., Wijma, B. and Swahnberg, K. (2012) Abuse in Health Care: A Concept Analysis. Scandinavian Journal of Caring Sciences, 26, 123-132.

https://doi.org/10.1111/j.1471-6712.2011.00918.x

[38] Guarinoni, M.G., Motta, P.C., Petrucci, C. and Lancia, L. (2014) Complexity of Care: A Concept Analysis. Ann Ig, 26, 226-236.

[39] Kalisch, B.J., Landstrom, G.L. and Hinshaw, A.S. (2009) Missed Nursing Care: A Concept Analysis. Journal of Advanced Nursing, 65, 1509-1517. https://doi.org/10.1111/j.1365-2648.2009.05027.x

[40] Meghani, S.H. (2004) A Concept Analysis of Palliative Care in the United States. Journal of Advanced Nursing, 46, 152-161. https://doi.org/10.1111/j.1365-2648.2003.02975.x

[41] Anderberg, P., Lepp, M., Berglund, A.L. and Segesten, K. (2007) Preserving Dignity in Caring for Older Adults: A Concept Analysis. Journal of Advanced Nursing, 59, 635-643. https://doi.org/10.1111/j.1365-2648.2007.04375.x

[42] Splaine Wiggins, M. (2008) The Partnership Care Delivery Model: An Examination of the Core Concept and the Need for a New Model of Care. Journal of Nursing Management, 16, 629-638. https://doi.org/10.1111/j.1365-2834.2008.00900.x

[43] Jenkins, B. and Warren, N.A. (2012) Concept Analysis: Compassion Fatigue and Effects upon Critical Care Nurses. Critical Care Nursing Quarterly, 35, 388-395.

https://doi.org/10.1097/CNQ.0b013e318268fe09

[44] Coffey, S. (2006) The Nurse-Patient Relationship in Cancer Care as a Shared Covenant: A Concept Analysis. Advances in Nursing Sciences, 29, 308-323. https://doi.org/10.1097/00012272-200610000-00005

[45] Nelson, H.L. (1992) Against Caring. Journal of Clinical Ethics, 3, 8-15.

[46] Wilson, C.B., Martin, K. and Esposito, J. (2015) Embracing the Difference Caring Makes: Implementing Caring Groups in a New Graduate Orientation Program. International Journal for Human Caring, 19, 27-32. https://doi.org/10.20467/1091-5710-19.1.27

[47] Glaser, B.G. and Strauss, A.L. (1967) The Discovery of Grounded Theory: Strategies for Qualitative Research. Aldine de Gruyter, New York.

[48] Watson, J. (2009) Postscript: Thoughts on Caring Theories and Instruments for Measuring Caring. In: Watson, J., Ed., Assessing and Measuring Caring in Nursing and Health Sciences, Springer Publishing, New York, 271.

[49] Bailey, D.N. (2009) Caring Defined: A Comparison and Analysis. International Journal for Human Caring, 13, 16-31.

[50] Phillips, P. (1993) A Deconstruction of Caring. Journal of Advanced Nursing, 18, 1554- 
1558. https://doi.org/10.1046/j.1365-2648.1993.18101554.x

[51] Sargent, A. (2012) Reframing Caring as Discursive Practice: A Critical Review of Conceptual Analyses of Caring in Nursing. Nursing Inquiry, 19, 134-143.

https://doi.org/10.1111/j.1440-1800.2011.00559.x

[52] Paley, J. (2001) An Archaeology of Caring Knowledge. Journal of Advanced Nursing, 36, 188-198. https://doi.org/10.1046/j.1365-2648.2001.01959.x

[53] Bredlow, T.S. (2013) Analysis, Evaluation, and Selection of a Middle Range Nursing Theory. In: Peterson, S.J. and Bredow, T.S., Eds., Middle Range Theories: Application to Nursing Research, Lippincott Williams and Wilkins, Philadelphia, 38-50.

[54] Tonges, M. and Ray, J. (2011) Translating Caring Theory into Practice: The Carolina Care Model. Journal of Nursing Administration, 41, 374-381.

https://doi.org/10.1097/NNA.0b013e31822a732c

Submit or recommend next manuscript to SCIRP and we will provide best service for you:

Accepting pre-submission inquiries through Email, Facebook, LinkedIn, Twitter, etc.

A wide selection of journals (inclusive of 9 subjects, more than 200 journals)

Providing 24-hour high-quality service

User-friendly online submission system

Fair and swift peer-review system

Efficient typesetting and proofreading procedure

Display of the result of downloads and visits, as well as the number of cited articles

Maximum dissemination of your research work

Submit your manuscript at: http://papersubmission.scirp.org/

Or contact ojn@scirp.org 